\title{
Travellers Under the Southern Cross: \\ Australian Show People, National Identities and Difference
}

\author{
P. A. Danaher \\ School of Education and Innovation \\ Faculty of Education and Creative Arts \\ Central Queensland University \\ Rockhampton Mail Centre QLD 4702
}

Telephone: (07) 49309281

Facsimile: (07) 49309604

E-mail: p.danaher@cqu.edu.au

P. A. Danaher is Foundation Senior Lecturer in Open and Distance Learning in the Faculty of Education and Creative Arts at Central Queensland University and the editor of Beyond the Ferris Wheel: Educating Queensland Show Children (Central Queensland University Press, Rockhampton, 1998) 


\title{
Travellers Under the Southern Cross: \\ Australian Show People, National Identities \\ and Difference
}

\begin{abstract}
This paper focuses on the travelling show people whose itineraries take them to every Australian State, including two circuits through Queensland. Show people evoke ambivalence in most permanent residents. Their itinerancy makes them different: they are considered exotic and even glamorous, yet they are also objects of suspicion, appearing to have no economic or emotional investment in the towns through which they travel. They are at once 'larger than life' and 'not like us'. For the show people's part, they are proud of their distinctive lifestyle and heritage, yet they also emphasise the points of similarity between themselves and other Australians.
\end{abstract}

The paper uses the author's interviews with, and representative publications by and about, show people to analyse the nexus between relations between 'showies' and 'locals' and the ongoing construction of national identities and difference. The show people's depiction of themselves is a strong contribution to the diversity of national identities, and their emphasis on their distinctiveness points to one possible way of celebrating difference within the framework of those identities. At the same time, the show people's tactic of emphasising their similarities with other Australians highlights how easily difference of identities can lead to marginalisation and discrimination. 


\section{Introduction}

I am writing a revised draft of this paper on 26 January 2001 in the Queensland regional city Rockhampton. This is a public holiday for most Australians, Australia Day in the year of the centenary of Federation for many Australians, and Invasion Day for some Australians. This complex variety of attitudes to a single date encapsulates some of the themes to be explored in this paper.

In particular, these responses suggest that, rather than there being a single Australian national identity, there are multiple identities of the Australian nation. That is, the various permutations of age, class, culture, employment, ethnicity, gender, location (including State and region), political affiliation, religion and sexual orientation constitute a rich tapestry of difference on which the diversity of Australian national life and lives can be displayed and enacted.

Yet matters are not nearly as simple as this utopian vision represents. This is because of the continuing effect of the 'invisible centre' (Ferguson 1990) that constructs some groups as 'normal' and others who depart from that 'norm' as 'deviant'. Thus middle aged, middle class, heterosexual, white men, for example, generally have greater cultural and financial capital than other groups who embody different, and differently valued, attributes and characteristics.

This privileging of some groups over others spills over into representations of national identities. In the late 1990s, a Commonwealth Government television advertising campaign to market Australia to overseas tourists featured 'bronzed 
Aussies' and sun, sea and sand. When challenged that these images excluded many other aspects of Australian life, the campaign directors responded that they needed something that 'worked'. Once again, the diversity of Australian national identities was reduced to a very narrow range of positively valued signs, thereby further marginalising groups who differ from that range.

This paper explores the 'place' in the identities of this nation of a group of Australians who are itinerant for large parts of the year - who are Travellers under the Southern Cross. Show people follow a large number of circuits that traverse the metropolitan and provincial cities and hundreds of country towns throughout Australia, including two 'runs' through coastal and central western Queensland. These are the people who bring sideshow alley to town, including 'joints' such as shooting galleries and rides such as ferris wheels. They are also associated with the stalls selling plush toys and the canteens providing fairy floss and hot dogs. While they travel the same circuits as the performers of equestrian displays, the two groups tend to lead relatively separate lives.

The show people are recognised as dispensing an invaluable service, particularly in rural areas, where the show often marks 'the one day of the year' that brings all the local people together (Roe 1998). On the other hand, the show people feel themselves to be marginalised from local people on account of their itinerancy, which associates them with images of Gypsies and vagabonds (Danaher 1998). They respond to this situation by engaging in various tactics (de Certeau 1984) designed to stress their commonality with other Australians while maximising the prospects of survival of their difference. Thus their appeals to images of 'typical Australians' and 
national identities are intended to ensure that they have a legitimate 'place' within those identities and hence an appropriate share of cultural and financial capital. At the same time, the fact that such tactics are necessary reflects the ease with which certain national identities are devalued and sometimes elided as debates about the meaning of 'being Australian' continue. 
From this perspective, show people are Travellers under the Southern Cross. By this I mean that they travel through most parts of Australia, and they are seen by local people as being 'Travellers' and 'of no fixed abode'. In fact, show people belong to a highly diverse community with internal differentiation based on such factors as occupational group, status and longevity on the show circuits. (They also differentiate themselves from other kinds of occupational Travellers, such as circus people and seasonal fruitpickers.) Some show people live permanently in standardly equipped caravans; others travel in luxuriously appointed vans and also have permanent homes in cities such as Sydney, Brisbane and the Gold Coast (Danaher 1998).

Despite this internal differentiation, show people present a 'united front' to outsiders. This is because they are conscious of generations of at best incomprehension and at worst discrimination on the part of locals on account of the show people's itinerancy. It is this consciousness that prompts them to engage in tactics to contest and subvert their marginalised status.

One such tactic is the show people's tendency to highlight their similarities to other Australians. For example, they like to emphasise their strong links with Australian rural communities (Danaher, 1997), some of which they help to keep alive by stimulating an annual circulation of money. They also claim to embody traditional family values and a pioneering spirit that they conceive as ‘typically Australian'. These similarities are designed as an 'antidote' to the perception that show people are different from, and therefore inferior to, the 'norm' of fixed residence in an Australia where home ownership has generally been regarded as one of the markers of 
respectability and success. The next two sections of this paper trace some of the manifestations of this interplay among national identities, difference and marginalisation, first in the author's interviews with show people, then in selected publications by and about show people.

\section{Interviews}

As part of a broader collaborative project (Danaher, 1998), between 1992 and 1996 I interviewed thirty-seven show people in five Queensland cities, as the show people moved along the two Queensland circuits. ${ }^{i}$ Rather than taking what the interviewees said 'at face value', I recognised that they were using the interviews as another tactic to subvert their marginalised status, by emphasising the positive features of itinerancy and their legitimate right to equitable access to services.

A crucial element of that tactic was the show people's consciousness that they are perceived by local people as 'strange', and their ongoing efforts to 'set the record straight'. A show person recalled the local incomprehension of the show people's need to have equipment serviced quickly:

See, I'll come in with a broken TV on Monday and say, 'Excuse me, I need it by Friday'. They look at you, because people put them in for a month. They can't understand that way. See, I'm moving onto another town, but they don't understand that part...They might think it's a bit weird, but we've only got so long in here, and we've got to do the best we can in those few days. (Y4P6) ${ }^{\mathrm{ii}}$ 
This reference to local people thinking that 'it's a bit weird' resonated with another show person's reflection on the show people's interactions with government officials:

And sometimes when we're talking to government bodies and that, they can't understand that it's urgent for us. It's always urgent, because that is the way that our business functions. (Y4P5)

Similarly, another show person stated in an interview with me: 'Because our lives it's a very sort of strange life to somebody like you' (Y4P1).

Following the argument outlined above, these references to perceptions of the show people as 'weird' and 'strange' reflected their awareness that their itinerancy marks them as 'different'. The result is that they are subject to the gaze of surveillance while they are 'in town'. For the show people, this process of objectification takes place every time that they enter a new community. The regularity and the repetition of enduring this kind of interested and objectifying gaze are marginalising in their cumulative effect.

This consciousness of the marginalisation that arises from being seen as 'weird' and 'strange' certainly underlay a ten year old girl's comment about local children: '...sometimes they don't understand that we're more or less like them but just travel on' (Y1C4). A show parent expressed this lack of understanding as amounting to 'a stigma': 'Like a lot of people are ignorant to our lifestyle and to the way things work, and they think that things aren't right, and that can cause a stigma' (Y1P2).

It is important not to underestimate the deleterious effects of this construction of show people as 'strange' and even as objects of pity. This process represents an 
insidious devaluing of the show people's lifestyle, and a refusal to concede their right to attach their own values to the way that they live and work. It therefore marks them out as 'different' and 'deviant', and accordingly as warranting the intrusive attention and surveillance of 'the centre'. Objectified pity brings with it less, not more, understanding of the show people, and it therefore contributes directly to their experiences of marginalisation.

It was against the backdrop of, and as a tactic of resistance of, this kind of marginalisation that one showman referred to the older generation of show people:

But overall they were learning worldly goods and products and way of lives. As Tex Morton [an Australian country and western singer] once said, 'Show me a showman's son or daughter and there's no fools amongst them'. He sang a song about them. They were [such] good children, they adapted to other things. (Y4P3)

This adaptability and the show people's striving for success led the respondent to claim 'that we' re the most organised body of people in this country' (Y4P3). He contrasted this situation with the years immediately after the second world war, when the show circuits were 'a small industry...and when we had a lot of Gypsies in it and so forth' (Y4P3). This catalogue of quintessentially Australian virtues - thrift, frugality, persistence, organisation - was presumably absent from the activities of the 'Gypsies'. Here simultaneously the speaker was connecting show people with timeless qualities of 'Aussie battlers', and dissociating show people from the negative stereotype that forms many Australians' perceptions of show people. Equally clearly, this distinction between show people and Gypsies reflects the persistence of racially 
exclusive, rather than inclusive, dimensions of national identities among specific Australian communities.

Another show person responded to hypothetical 'doubting Thomases' in her explanation of her enjoyment of life on the show circuits:

I must be biased, because I think we have the best lifestyle. We have everything. We have Australia's most beautiful places that we see every year. We have travelling, life, colour, movement, all in our world...So I think we have a better lifestyle than most people when they say, 'How could you do it?'. Like it's so terrible. We're lucky. We love what we're doing, we spend time with our family, because our business is a work at home business, more or less. (Y4P5) 
This self-confident articulation of the special benefits of being show people functions on at least two levels. Firstly, the speaker's statement is a riposte to those whose stereotypical response to show people is suspicion tinged with pity, by suggesting that in many ways the show people's lifestyle is 'better' than that of 'most people'. Secondly, the subtext of the statement is less competitive boastfulness than seeking to evoke some common identification through the use of supposedly universal tropes such as 'family', 'business' and 'home'. So this person's tactic is to emphasise similarity with other Australians at the same time that she celebrates the show people's difference, all in the context of multiple national identities.

A similar intention was manifested in a different kind of tactic: the show people's use of political connections and networks. Another respondent explained: And of course there's a lot of politicians who like to be seen to be mixing with showmen. They like to be seen riding the rides. It's some macho image, of being the premier driving the dodgem cars with his kids. It's the basis of family entertainment, and of course on the front page of the Courier Mail [Brisbane's daily newspaper]...the [former] premier was photographed with his son driving the dodgem cars, and of course the image that portrayed to the public was here is a normal average Australian bloke with his son on the dodgem cars at the show. You can't get any more traditionally Australian, and they like that image, and they want that image. And that's how it all works in. (Y4A1) 
Here the speaker revealed his understanding of how politicians deploy a similar tactic to that used by show people (although it is doubtful that politicians belong to a 'marginalised' group, at least in the sense used by de Certeau [1984]). The presumption is that being seen as 'normal', 'average' and 'traditionally Australian' is the means to cultural capital, whether the technique is performed by politicians or show people. The obverse of this situation, however, is that both politicians and show people use the technique simultaneously to draw attention to their 'special' status - respectively as leaders gifted with the 'common touch' and as people who earn their living by travelling.

\section{Selected publications}

These themes are also evident in selected publications by and about show people. For example, one chapter of Bob Morgan's oral history of several show people, The Showies (Morgan 1995), dealt with Jack Allan, who joined the show in 1928 at the age of fourteen and who developed a very successful career as, among other roles, a 'spruiker' (a 'front man' charged with attracting the crowds to a particular act) and a promoter of the wrestler Chief Little Wolf. In a representative passage about Jack and his wife Dawn, Morgan wrote:

...they have the satisfaction of knowing that they were a part of those magnificent people who brought so much joy and entertainment to the multitude of Australians who were so dependent on them and their kind for decades - from the Depression days of the 1930s through the dark days of the Second World War, and into the post-war years leading up to the advent of television. (Morgan 1995: 112) 
Morgan's eulogy ranks almost as a mission statement for past and present show people: the public entertainment of the Australian people, through good times and bad. Thus the show people provided a public service, cheering up people during the 'dark days' of depression and war, and bringing them 'joy and entertainment' before the invention of television - the suggestion being that the show people's special relationship with the public was irretrievably altered, even if not destroyed, by television.

Morgan's statement evokes something of a 'golden age', in which the show people indispensably fulfilled the public's needs and by implication were lauded rather than devalued for their difference and thereby contributed something unique and fundamental to Australian national identities. This kind of evocation is used by show people as a 'call to arms' to present day descendants from this 'golden age', as a tactic of uniting what I explained earlier is a very diverse and complex community and thereby of subverting strategies to marginalise that community.

Several examples of this tactic at work can be found in the quarterly national magazine The Outdoor Showman, produced by the Victorian Showmen's Guild. Many articles in the magazine reflect the "showies"' conviction that they have a specialised and valuable lifestyle - a conviction that has considerable impact on their attitudes to and experiences of marginalisation. For example, a New Zealand 'showie' wrote in the 'Letters' page:

We can be perceived by others as strange. We are both divided and united. Anywhere in the world you would be greeted warmly by show families 
without prejudice. I read letters from old show people worldwide and the stories are similar to our own. Sad that their friends have passed on and happy that our new generations are coming through to carry on with this wonderful profession. (Ashworth 1997: 7)

The fact that this letter was written by a New Zealander gives special point to the assertion that 'We can be perceived by others as strange'. In other words, being rejected by one's fellow citizens contrasts with a sense of identification with 'showies' in other countries. This is a construction of marginalisation with which 'mainstream' Australia would not be familiar. The last sentence of the paragraph emphasises the importance of passing on the cultural traditions of 'this wonderful profession' to the members of 'our new generations'. Here again is the assertion of making a specialised contribution to national life that is not necessarily appreciated by other citizens.

Similar feelings were evident in Lew Osborne's (1997) retrospective essay 'Behind the loudspeakers, toffee apples and fairy floss'. A clear example was evident in the concluding paragraph of that essay:

The atmosphere, this magic that is created is unique to shows and can only get better as we strive to hold a place in a rapidly changing world and it's happening right now, behind the loudspeakers, toffee apples and fairy floss. (Osborne 1997: 21)

This rhetorical flourish is characteristic of many of the articles in The Outdoor Showman. The intention is clearly to depict shows as 'unique' in creating 'this 
magic', which is evoked by such powerful images as 'the loudspeakers, toffee apples and fairy floss'. The optimistic belief in progress - 'this magic...can only get better' - contrasts with the slightly ominous reference to the need to 'strive to hold a place in a rapidly changing world'. This last point is particularly important. The writer has constructed 'a place' as the show people's 'portion', their equitable share of the available resources. That 'place' exists independently of the show people's itinerant lifestyle, which means that their 'place' changes from one week to the next. This recalls de Certeau's (1984) assertion that marginalised groups deploy tactics in the 'place' of 'the other' - that is, on the terrain of the forces of marginalisation. In other words, the insistence that show people are special or 'unique' - the emphasis on their difference - is combined with an effort to identify with other Australians, including their presumed right to a 'fair share' of national resources.

The spirit of this ambivalence about identity and difference was captured in the historical study Sideshow Alley (1998), a collaboration between Australian historian Richard Broome and Indigenous Australian travelling boxer and wrestler Alick Jackomos. The authors' account of the rise and fall of 'sideshow alley' referred not to the joints and rides that that term evokes today, but instead to the 'alley of wonder' that comprised animal acts, boxing troupes (many of whose members were Indigenous Australians), 'freak' shows and illusion acts. The authors emphasised the resistant agency of the itinerant inhabitants of 'sideshow alley', arguing that their extended family provided a refuge from a marginalising broader community and a recognition of skills that were not valued outside the 'alley':

A dominant theme of the book is that Sideshow Alley was a place of power for its participants. This may seem surprising given that showpeople were 
viewed by the rest of society with both fear and wonder, and as outcasts. However, showpeople evolved their own culture over generations and this enabled them to forge their own self-assured identities and a unique way of life...Seen in their own terms there are few victims in Sideshow Alley. (viii)

At the same time, Broome and Jackomos recognised that ambivalence was evident in other Australians' views of the inhabitants of 'sideshow alley':

Sideshow Alley was also a place of power for other Australians. Those who did not visit it demonised it as a powerful place of low and dangerous entertainment. Those who frequented Sideshow Alley found it a powerful source of wonder in their lives. For both groups it helped to shape their identities by gazing at difference; because human identities are formed partly by knowing, seeing and experiencing difference. We know who we are, in both a positive and a negative sense, by that which we are, as well as by that which we are not. (p. viii)

This assertion in many ways encapsulates the complex connections among the show people's tactics of subversion, their difference and their contributions to Australia's multiple national identities. It also highlights the considerably varied extent to which those multiple national identities are recognised and valued. 


\section{Conclusion}

So as the sun sets on 26 January 2001 in a Queensland regional city it is appropriate to ask what, if any, are the implications of the argument propounded in this paper for the multiple dimensions of Australians' national identities that invest this particular date with so many contradictory meanings. My response to this complex issue is to argue for an expansion of agency as conceptualised by Hudson and Bolton, for whom 'The concept of Australia has been, and continues to be, created on the basis of traits and achievements which can only be explained for the most part by Australian agency' (Hudson and Bolton 1997: 2). They elaborated what they meant by this assertion:

In so far as the essays in this volume emphasise the originality, independence and agency of Australians, they imply a distinctive response to the question of what Australian history should now be. Without retreating in any way from the need for subversive and socially critical history, they imply that Australian history can help to create Australia precisely by acknowledging the creativity and originality of Australians. (Hudson and Bolton 1997: 10)

Although I am sceptical about the 'national genius' overtones of the end of the quotation, I concur that focusing attention on agency highlights part of the way forward in relation to Australia's multiple national identities. This agency underpins the various tactics of subversion that were discussed in my account of show people's interactions with other Australians. Those interactions follow de Certeau's (1986) conception of them as tactics used by marginalised people to insert themselves, 
however temporarily, into the 'place' of 'the other'. That is, they derive from the show people's determination to celebrate their difference while pointing to their similarities with their fellow citizens. From this perspective, the show people's depiction and communication to others of their identities is a significant contribution to the diversity of Australian national identities. Furthermore, their emphasis on what makes their identities distinctive is one possible way of celebrating difference within the framework of those identities.

As in the case of their analysis of multiple identities (which downplayed the fact that some identities are more highly valued than others), however, Hudson and Bolton's (1997) account of agency is only half the story. By this I mean that agency needs to be combined with political will to change by people who are complicit in rendering certain groups marginalised. The show people have been able to lobby politicians, for example, both because their agency makes them self-confident and articulate and because politicians perceive it as being in their own interests to listen to the show people; other minorities are not so fortunately placed.

Accordingly, as I asserted above, agency alone is not enough; it must be joined with a genuine commitment to changing the conditions and structures of marginalisation. Otherwise, Australia's multiple national identities will continue to treat some people's difference as 'diversity' and other people's difference as 'deviance'. This underscores the ease with which difference of identities can lead to marginalisation and discrimination. Of course, this 'insight' is nothing new to the show people those Travellers under the Southern Cross - who have realised and responded to this 'truth' for generations. 


\section{Works Cited}

Ashworth, A. "Letter.” The Outdoor Showman, No 404 (April-June 1997): 7.

Broome, Richard with Jackomos, Alick. Sideshow Alley. St Leonards: Allen \& Unwin, 1998.

Danaher, P. A. “Showing the Way.” Community Quarterly, No 43 (June 1997): 3338.

Danaher, P. A. (Ed). Beyond the Ferris Wheel: Educating Queensland Show Children (Studies in Open and Distance Learning Number 1). Rockhampton: Central Queensland University Press, 1998.

De Certeau, Michel. The Practice of Everyday Life (trans. by Steven Rendall). Berkeley: University of California Press, 1984.

Ferguson, Russell. “Introduction: Invisible Center.” In Russell Ferguson, Martha Gever, Trin T. Minh-ha and Cornel West (eds), Out There: Marginalization and Contemporary Cultures. New York and Cambridge, Massachusetts: The New Museum of Contemporary Art and the Massachusetts Institute of Technology Press, 1990: 9-14. 
Hudson, Wayne and Bolton, Geoffrey. "Creating Australia." In Wayne Hudson and Geoffrey Bolton (eds), Creating Australia: Changing Australian History. St Leonards: Allen \& Unwin, 1997: 1-11.

Morgan, Bob. The Showies: Revelations of Australia's Outdoor Side-Showmen. Mitcham: self-published, 1995.

Osborne, Lew. "Behind the Loudspeakers, Toffee Apples and Fairy Floss." The Outdoor Showman, No 405 (1997): 21.

Roe, Jill. "Belly-dancing in the Bush, and Other Strategies for Survival." Australian Historical Association Bulletin, No 87 (1998): 12-24. 


\section{Acknowledgments}

I am grateful to the show people, and to their children's teachers and home tutors, who have talked to me about identities and difference. Mr Dick Dargin, Executive Officer of the Showmen's Guild of Australasia, corrected a couple of misapprehensions about the organisation of the show circuits. Dr Leonie Rowan has provided invaluable advice about the doctoral study on which part of this paper is based; the paper has benefited considerably from suggestions for improvement by two anonymous reviewers and by Dr Geoffrey Danaher. Interviews were transcribed by Dr Danaher, Ms Bonita Frank and Ms Pam Gale. The paper is part of a larger project researching Australian Traveller education; I acknowledge the ongoing collaboration of my current and former fellow researchers at Central Queensland University. 
i. Although the broader project of which this paper forms a part focused principally on educational issues, it also involved such topics as identity formation.

ii. For the purposes of preserving the anonymity of respondents, while indicating to the reader which statements were made by particular respondents, I have identified interviewees' quotations with codes. In the codes, 'Y' refers to the year of the project in which the interview was conducted, while ' $\mathrm{A}$ ', 'C' and 'P' denote the number of the interviews conducted respectively with administrators, children and parents. 